\title{
Death Toll by Dementia Drug
}

Jong-hoon Lee ( $\nabla$ science@research.re.kr)

Seoul National University College of Medicine https://orcid.org/0000-0003-1775-5656

\section{Research Article}

Keywords: Dementia Management Act (DMA), Alzheimer's disease (AD), anti-AD drug (AAD) groups, death toll

Posted Date: May 4th, 2021

DOI: https://doi.org/10.21203/rs.3.rs-384861/v4

License: (ㅇ) This work is licensed under a Creative Commons Attribution 4.0 International License. Read Full License

Version of Record: A version of this preprint was published at Naunyn-Schmiedeberg's Archives of Pharmacology on February 5th, 2022. See the published version at https://doi.org/10.1007/s00210-022-02209-3. 


\section{Abstract}

The Dementia Management Act (DMA) came into effect on August 4, 2011, in South Korea. Medical data on the correlation between Alzheimer's disease (AD) and anti-AD drug (AAD) groups were observed from 2010 to 2019. This study investigated the increase and decrease in deaths and $A A D$ used to treat $A D$. It is known that psychotropic medicines should not be administered for dementia patients because they increase all-cause mortality. This study demonstrated that acetylcholinesterase inhibitors and N-methyl-D-aspartate (NMDA) receptor antagonists increase the death toll when used to treat dementia.

\section{Introduction}

National data about mortality in people with specific disabilities provides a basis for public health interventions. Life expectancy is data accumulated over decades. Linked mortality data using medical records to identify people with specific disabilities like leprosy and intellectual disabilities could provide comprehensive unbiased population-based monitoring in spite of the circumstances of illnesses or death ${ }^{1,2}$.

According to the Dementia Management Act (DMA), the Sorokdo National Hospital, established to treat leprosy in May of 1916, has provided Alzheimer's disease (AD) treatment and preventive services for Hansen's disease (HD) patients. There were HD patients who just settled in 2020 to those who had lived most of life for 79 years in Sorok Island. The decrease or increase of life expectancy of HD patients is fundamental data ${ }^{3-5}$. The life expectancy of HD Patient in South Korea is known to live longer than life expectancy of Koreans ${ }^{6}$. Some studies lead our understanding for HD patients' longevity to the effects of dapsone (4,4'-Diaminodiphenyl Sulfone, DDS) which is one of multi drug treatment therapy for leprosy ${ }^{7-10}$. It should be very peculiar, but it needs to be examined thoroughly.

The DMA's purpose is to mitigate personal pain and damage from dementia. The DMA came into effect on August 04, 2011, in South Korea, and it was amended on June 12, 2018 ${ }^{11}$. Medical personnel, psychiatrists, or neurologists of medical institutions and workers engaged in providing medical services under the Medical Service Act became very active in the dementia management programmes being executed by the state and local governments. According to the DMA policy, AD patients and AAD prescriptions are increasing rapidly, so it is most necessary to analyse national medical data. AAD group 1 is dementia symptom treatments: donepezil hydrochloride, rivastigmine, galantamine, and NMDA receptor antagonists. AAD group 2 includes psychotropic medications such as haloperidol, risperidone, quetiapine, olanzapine, aripiprazole, oxcarbazepine, fluvoxamine, escitalopram, trazodone, sertraline, and fluoxetine.

South Korea's electronic data interchange (EDI) medical procedure code is well-computerised for health insurance claims data ${ }^{12}$. General practitioner in South Korea currently identify the patients as having $A D$ and taking $A A D$ through EDI. This study investigated the changes in the numbers of deaths and the $A A D s$ used to treat $A D$ in the National Health Insurance System (NHIS) of South Korea. With the increasing biomedicalisation of dementia, we have announced that it can treat dementia or slow the disease's progression ${ }^{13-18}$. The prescriptions for AAD have increased dramatically, and now the results need to be examined.

\section{Results}

Compared with South Koreans' increased life expectancy, there was a gradual decline in HD patients' life expectancy in 2005-2019. HD patients taking AAD group 2 together with group 1 had a shorter lifespan than those taking AAD group 1 alone (Fig. 1). The mean age of deaths while taking the treatment for dementia symptoms only (AAD group 1 ) is shown blue in the figure. The mean age of deaths while taking additional psychiatric drugs (AAD group 2$)$ is red. In 2018-2019, the life expectancies of HD patients taking additional psychotropic medications suddenly dropped in Sorokdo National Hospital. This is presumed to be because a public health doctor was working during 2017-2019 in Sorokdo National Hospital to substitute military services to administer AAD group 2 thoroughly.

However, the life expectancies of HD patients taking AAD group 1 (blue) also decreased in Sorokdo National Hospital. On the other hand, the life expectancy of the general Korean population is on the rise. Thus, it can be estimated that AAD group 1 reduces life expectancy.

\section{First-NHIS-Retrieval Results}

From 2010 to June 2019, the DMA increased the diagnosis of patients with MCl or AD by 3.26 times and AAD prescription by 4.65 times in South Korea (Fig 2).

We requested and analysed the entire ICD 9 and 10 code data (from 2010 to 2019) of AAD and deaths from the NHIS with the Open Data Mediation Committee of South Korea according to the Official Information Disclosure Act in South Korea. NHIS provided the information of deaths (Table 1). The number of users who took AAD in Korea increased by 2.16 times, and the number of deaths increased by 2.51 times from 2010 to June 2019 (Fig. 3 ). This number of $A A D$ and deaths is the baseline.

The number of users who took donepezil in Korea increased by 3.48 times, and the number of deaths increased by 3.88 times from 2010 to June 2019 . The number of users who took rivastigmine in Korea increased 1.84 times, and the number of deaths increased by 2.36 times from 2010 to June 2019 . The number of users who took memantine in Korea increased 2.50 times, and the number of deaths increased by 2.29 times from 2010 to June 2019 . The number of users who took risperidone in Korea increased 1.26 times, and the number of deaths increased by 1.35 times from 2010 to June 2019 . The number of users who took galantamine and other psychotropic medications in Korea increased 1.55 times, and the number of deaths increased by 1.60 times from 2010 to June 2019.

Doctors do not prescribe Cholinesterase inhibitors (ChEls: donepezil, rivastigmine, galantamine) or memantine duplicate to patients. They add AAD group 2 to patients; this study analysed the deaths of group 1 (Table 2). The output of the ANOVA Calculator is significant. The F-ratio value is 62.7191 . The $p$-value is 
$<.00001$. (The result is significant at $p<.05$.) And the values of the Friedman X2r is $30(3, N=10)$. The $p$-value is $<.00001$. The result is significant at $p<.05$. (Supplement. Statistics Table 19-1)

The increased use of donepezil, rivastigmine and memantine increased the death toll (Fig. 3). However, rivastigmine had a significant difference in the increase or decrease in users from 2014 to 2019. Moreover, memantine did not show a considerable increase in the number of deaths than the increase in users. So, we needed a comparison graph for hidden data.

\section{Second-Data-Processing results}

We developed an equation to interpret the data for this study. By comparing the rate at which the number of deaths increases when the number of users increases, we can compare deaths caused by dementia medicines.

[Lee's hidden equation for a comparison graph]

$X$ is the year, $Y$ is (death $B$ - death $A) /($ user $B$ - user $A$ )

We calculate the independent variables: AAD, Donepezil, Rivastigmine, Memantine, Risperidone, Fluoxetine, Olanzapine, Sertraline, Quetiapine, Aripiprazole, Escitalopram, and the others by Lee's hidden data calculator. (Table 3) (Fig. 4)

The population are all Koreans. The number of deaths is the independent variable. It makes to calculate the F-ratio value and the $\mathrm{p}$-value by One-Way Repeated Measures ANOVA Calculator. If there are five independent variables (AAD, Donepezil, Rivastigmine, Memantine, Risperidone), the dependent variable is Lee's hidden data. The output of the ANOVA Calculator is significant. The F-ratio value is 3.2028 . The $p$-value is .023868. (The result is significant at $p<.05$.) (Supplement. Statistics Table 20-1)

We used AAD as the reference line. Although rivastigmine was rapidly increased and decreased death rates, it was the drug that increased the death rate according to the trend line. Memantine did not increase the number of deaths than the increase of users: The number of users increased 2.50 times, and the number of deaths increased by 2.29 times from 2010 to June 2019. However, when the hidden equation was used, memantine also increased the death rate (Fig. 5).

\section{Discussion}

This study was conducted from 2005 to 2020 based on the medical records of Sorokdo National Hospital. However, this study was initiated in February 1962 by Sister Marianne Stoeger and Sister Margaritha Pissarek. They left Sorok island on November 21, 2005, returned to their homeland. They stayed for 40 years with exceptional compassion for their patients. However, the average life expectancy of HD patients began to decline overall in the four groups from 2005 after they left (Fig. 6). The life expectancy of HD patients was longer than that of Koreans because of taking dapsone ${ }^{6-10}$. Even more embarrassing, the group's life expectancy taking AAD (red and black) was higher than that of the group not taking AAD (blue and green), and all four groups tended to decrease. Groups that were not taking dapsone (green) live longer than groups taking dapsone (blue). After President Dae-Jung Kim came to power in 1998, they were guaranteed freedom. As more and more became smokers, as in a typical rural village, respiratory infectious diseases increased ${ }^{19}$. It is natural for people with stronger hearts and health to live longer, and AD was more prevalent in those who lived longer. The control group on Sorok Island, created by the two sisters for 40 years, shows that death tolls are more important than life expectancy for studying AAD and deaths. The AD2000 Collaborative Group's research already reported the following results in 2004.

Donepezil is not cost-effective, with benefits below minimally relevant thresholds ${ }^{20}$. There were no significant results: between donepezil and placebo in adverse events or deaths, formal care costs, unpaid caregiver time, carer psychopathology, behavioural and psychological symptoms. There was also no significant difference between $5 \mathrm{mg}$ and $10 \mathrm{mg}$ donepezil. More effective treatments than cholinesterase inhibitors are needed to treat AD. ChEls and memantine do not reduce the progression rate of Alzheimer's disease ${ }^{21-25}$. AD patients who received ChEls and memantine took them for longer, were more functionally impaired, and showed more significant cognitive decline than those who only received ChEls ${ }^{26}$. When we assess the hazard of death in persons with and without amnestic mild cognitive impairment $(\mathrm{MCl}), \mathrm{MCl}$ is associated with increased mortality ${ }^{27}$. They tended to take ChEls more than without amnestic $\mathrm{MCl}$ persons. The DMA reinforced the socialisation of elder care, and the enduring fear of dependency in old age forced Koreans to cooperate in diagnostic tests and treatments for dementia actively ${ }^{28}$. It is well understood that individual Koreans are very active in the prevention of SARS-CoV- $2^{29}$.

\section{Korean Government's Legislative Process and Medical Staff Medication}

The Korean government has established national policies for dementia care, and compulsory long-term care insurance for older people was introduced ${ }^{30}$. The 'War against Dementia' and the First National Dementia Plan was announced in $2008^{31}$. It facilitates the socialisation of long-term care services at a national level. The DMA was legislated in August 2011. The government announced the DMA as a reform plan, emphasising changes such as increasing coverage and improving the quality of services ${ }^{30}$. The DMA intended to lighten its burden on society and help enhance national health by establishing and implementing comprehensive policies on preventing dementia, supporting dementia patients, and researching finding a cure for dementia.

As a result of the election in May 2017, the new president announced the National Duty for Dementia ${ }^{32}$. The proportion of elderly over 65 years exceeded $14 \%$ of the entire population in $2018^{33}$, and dementia care became a major national issue. The DMA was strengthened on June 12,2018 . The Korean government installed Community Dementia Reassurance Centers successively at all Community Health Centers to establish a community-based dementia management system according to the National Duty for Dementia. Psychiatrists or neurologists of medical institutions engaged in medical diagnosis and treatment under 
the Medical Service $\mathrm{Act}^{34}$. They strengthened the dementia management programs that administer AAD to $\mathrm{MCl}$ or delirium as a preventive and treatment ${ }^{35-39}$. They insisted that the 1-year persistence rate of ChEls for $A D$ patients should be specially monitored to optimise treatment persistence because patients are less likely to remain on therapy than those in other countries ${ }^{36}$. The no improvement results of clinical studies on AAD were already published in 2005200921-26. In Korea, medical staff started to publish clinical studies of ChEls and memantine as significant but modest therapeutic improvement in the year $2009^{35,40,41}$.

Furthermore, the media interviewed medical staff on whether the administration of AAD is essential to slow down and treat dementia ${ }^{42,43}$. By Article 12 (1) of the DMA, the government and local governments provided support for the treatment and diagnosis of dementia in consideration of the economic burden of dementia patients. NHIS began to reduce the cost of AAD drugs for dementia patients, and the drugs became almost free. From 2010 to June 2019 , policymakers and medical staff increased the diagnosis of patients with $\mathrm{MCl}$ or $\mathrm{AD}$ by 3.26 times and $\mathrm{AAD}$ prescriptions by 4.65 times in Korea.

\section{The Neurological Side Effects of ChEls for AD Patients}

The percentage of new users was $2.5 \%$ across hospitalizations for Alzheimer's medication ${ }^{44}$. Neuropsychiatric symptoms and adverse drug reactions were associated with significantly increased prevalence of further psychotropic medication use ${ }^{45}$, and hospital stays due to dementia and the need of care were predictors for new use of psychotropic medication ${ }^{46}$. All studies from many countries have already confirmed that antipsychotic drugs should not be administered to dementia patients because of the risk of seizures and all-cause mortality ${ }^{47,48}$. Deprescribing psychotropic medications are feasible for most people experiencing no withdrawal symptoms in long-term care ${ }^{49,50}$. Life expectancy is significantly different between AD and AAD groups 1 and 2 for 2018 2019 in the Sorokdo National Hospital (Fig. 1). It is suspected because the patients were hospitalised in the psychiatric ward, but the life expectancy of AAD group 1 is also decreased. Adverse events of ChEls were reported by $81.2 \%$ of 196 participants in the Comparative Research of Alzheimer's Disease Drugs ${ }^{51}$. However, the neurological side effects of ChEls for AD patients are similar to the neurological symptoms of AD patients. Few specialists can distinguish the side effects caused by dementia or donepezil drugs: dizziness, delusions, dream abnormalities, ataxia, convulsive seizures, hemiplegia, hypertonia, and salivation ${ }^{52,53}$. While monitoring the $A D$ patient's condition, acetylcholine precursor was prescribed in the hospital's intensive care unit to the patient who had a stroke but medical staffs were not aware of the neurological symptoms caused by the acetylcholine precursor' side effects (Fig. 7). If AAD itself was not staged as a biomarker (D), the patient was bound to a bed, and making the patient's condition worse ${ }^{54}$. When connected with the Sorokdo National Hospital's EDI database, we could evaluate AAD prescriptions for fifteen years ${ }^{55}$. Three ChEls are approved for use in mild to moderate AD, and their symptomatic benefit in $A D$ has been confirmed via meta-analyses assessing both cognitive performance and global functioning ${ }^{56}$. However, the data analysis on the number of people who took four FDA-approved therapeutics (three ChEls and memantine) and the number of fatalities revealed that the number of deaths increased as the number of prescriptions increased. NHIS did not separately provide the number of users and deaths of galantamine because of the pharmaceutical company's request, but it could be sufficiently estimated. Memantine did not show a significant increase in the number of deaths than the increase in users, but the death toll increased in the hidden equation graph (Fig. 5).

\section{We Should Re-Examine the Life Expectancy of Dementia Patients Treated by AAD}

We re-evaluated the effects of long-term accumulation of four FDA-approved therapeutics. ChEls' neurological side effects are very similar to AD neurologic symptoms ${ }^{52-54}$. Many unique ethical issues arise when treating $A D$, and psychiatrists are prone to pharmacological prescriptions for their ease of management of late-stage $A D$ patient ${ }^{57}$. Today, patients with Alzheimer's disease $(A D)$ tend to have more drugs prescribed and much older and frailer than some decades ago. According to the "evidence-based medicine issue", pushing clinical trials to anticipate its detection even before the appearance of its clinical manifestations may overshadow the person's values and priorities ${ }^{58}$. Donepezil, which most patients have taken, increased more patients with neurological abnormalities with heart failure ${ }^{53,59}$. Patients with neurological abnormalities are classified as severe AD because violence and abnormal behaviour are increased ${ }^{54}$. Clinicians promptly administer the AAD group 2 with restraining the patient, and the number of deaths from $A A D$ group 2 replaces the number of deaths from donepezil like Figs. 1 and 6 . It may explain why the mortality from donepezil relatively seems low when cognitive function is maintained partly by their cognitive effects by $\mathrm{ChEls}^{60}$. We watched the report of donepezil initiation associated with better survival benefit than other $A D$ medications (memantine and oral and transdermal forms of rivastigmine) from AD medication groups in a US national sample of Medicare beneficiaries ${ }^{61}$. But patients who caused side effects by donepezil was not recorded because they went to the ward to treat evolving neurological symptoms or heart failure with AAD group 2 or other managements, this study elucidates the direct effects of AD medications on mortality in real-world settings.

Dapsone has been mainly used in clinical studies on inflammasome competitors. When a patient taking dapsone stopped dapsone for stroke treatment and took acetylcholine precursors for dementia care, the patient's courses were rapidly exacerbated to severe hypertension and neurologic abnormalities ${ }^{62-64}$.

\section{Many Toxins are Cholinesterase Inhibitors}

However, many toxins are cholinesterase inhibitors, and these toxins can cause death if given at high enough dosages. There is no known cumulative effect on $\mathrm{AD}$ patients who have taken ChEls or memantine consistently for long periods. Botulinum toxin blocks the release of acetylcholine hormone from the presynaptic terminal by preventing acetylcholine release ${ }^{65}$. Black widow spider venom is thought to be associated with a wide release of neurotransmitters, especially norepinephrine and acetylcholine, due to spider envenomation. If widow venom exhausts all acetylcholine supplies as the opposite effect of botulinum toxin, paralysis occurs 66,67 .

Acetylcholine performs various physiologic functions through cholinergic muscarinic receptors; five different types of muscarinic receptors, M1, M2, M3, M4, and M5. The muscarinic receptor M1 is in the cerebral cortex, salivary glands, and gastric glands. The muscarinic receptor M2 is present in smooth muscle as well as cardiac tissue. The muscarinic receptor M3 is found in smooth muscle cells, particularly of the bronchioles, iris, bladder, and small intestines. The 
muscarinic receptors M4 and M5 have a less clear distribution but have been found in the hippocampus, substantia nigra, and other locations within the brain 68,69

The non-neuronal cholinergic systems are involved in the pathophysiology of diseases ${ }^{70}$. The cardiovascular system determines generalised vasodilation, negative chronotropic effects, and negative inotropic effects. It has a less pronounced negative dromotropic effect in the specialised tissue of the sinoatrial and atrioventricular nodes at the ventricular level than other organs. Muscarinic receptor 2 is not the only functional subtype found within the heart, and muscarinic receptors 1 and 3 mediate both dilation and constriction in the vasculature ${ }^{71}$.

When a patient taking dapsone, mainly used in clinical studies on inflammasome competitors ${ }^{19,55,72}$, stopped it for stroke treatment and administered acetylcholine precursors for dementia care, the patient's courses were rapidly progressed to severe hypertension and neurologic abnormalities ${ }^{54}$.

AADs administered to the elderly are closely related to health insurance policies. If the elderly die early, health insurance companies will benefit. However, health insurance policies have been implemented to improve the health of the elderly ${ }^{73}$. Long-term administration of ChEls to patients with dementia has increased mortality. The effects of ChEls on cardiovascular systems should be analysed and studied.

\section{Methods}

\section{Experimental Design}

According to the Official Information Disclosure Act in Korea, the Seoul study analysed AD and anti-Alzheimer's disease drug (AAD) used in Hansen subjects. We searched all medical records of the National Health Insurance Service (NHIS) in Korea when the Korean government computerised the International Classification of Diseases (ICD)-9 (10) code and Electronic Data Interchange (EDI). We also connected the medical record database of the Sorokdo National Hospital and archived it from January 2005 to June 2020. The Sorokdo National Hospital was established and operated exclusively for HD patients. Since HD patients take therapeutics for leprosy, a Seoul cohort runs to study AD and AAD correlations.

With the ICD-9 and -10 codes, medical data on the correlation between AD and AAD were then analysed for cohort correlational possibility. AAD First group, according to Korea Drug Code Medicine, First Group: For symptomatic relief of Alzheimer's disease (donepezil hydrochloride, rivastigmine, galantamine, Nmethyl-D-aspartate (NMDA) receptor antagonist). AAD Second group is according to Korea Drug Code Medicine Second Group: For psychologic symptoms of Alzheimer's disease (haloperidol, Risperidone, Quetiapine, Olanzapine, Aripiprazole, Oxcarbazepine, fluvoxamine, Escitalopram, Trazodone, Sertraline, Escitalopram, Fluoxetine). (Supplement 1. Korea Drug Code Medicine) The mean age of death of AD patients was classified into the first or second group.

Through the coordination of the Open Data Mediation Committee, data on the number of deaths among people taking AAD from 2010 to 2019 were available from the NHIS. We analysed the entire ICD 9 and 10 code data (from 2010 to 2019) of AAD and death from NHIS. We used the software programs ObjectRelational DBMS and Google spreadsheet for $\mathrm{R}^{2}$ analysis and power series calculations. (Supplement 2. DATA)

\section{Code Availability}

We used Google spreadsheets for $\mathrm{R}^{2}$ calculation and drawing the trend lines.

\section{Data Availability}

The authors declare that all primary data generated or analysed during this study supporting the findings are available in the article and supplement files. Additional data that support the findings of this study are available from the corresponding author upon reasonable request. Source data are provided with this paper: Center for Open Science (https://osf.io/z7ph2/).

\section{Data and Material Availability}

According to the Official Information Disclosure Act in Korea, it is possible to provide public access to a dataset based on the linkage of data from nationwide public registries. Access to the registry data of the National Health Insurance Service (NHIS), the Sorokdo National Hospital, and the Health Insurance Review and Assessment system can be granted to individual researchers only upon seeking approval, according to the National Agency for Data Protection. We therefore cannot place the dataset in a public repository. However, pooling of aggregated data is possible and would be of interest to the research group.

\section{References}

1. Butlin CR. Excess of deaths of leprosy-affected people. Lepr Rev 2020;91(2):220-223.

2. Glover G, Williams R, Heslop P, Oyinlola J, Grey J. Mortality in people with intellectual disabilities in England. J Intellect Disabil Res 2017;61(1):62-74. DOI: https://doi.org/10.1111/jir.12314.

3. Walker SL, Lebas E, Doni SN, Lockwood DNJ, Lambert SM. The mortality associated with erythema nodosum leprosum in Ethiopia: a retrospective hospital-based study. PLoS Negl Trop Dis 2014;8(3):e2690. DOI: 10.1371/journal.pntd.0002690.

4. Shen J, Liu M, Zhou M, Li W. Causes of death among active leprosy patients in China. Int J Dermatol 2011;50(1):57-60.

5. Ferreira AF, De Souza EA, Lima MDS, et al. Mortalidade por hanseníase em contextos de alta endemicidade: análise espaço-temporal integrada no Brasil. Rev Panam Salud Pública 2019;43:e87. DOI: 10.26633/rpsp.2019.87. 
6. Cho Y, Shim E, Lee KS, Park SC. Mortality profiles of leprosy-affected elderly in Korea: a demographic perspective. Asia-Pac E-J Health Soc Sci 2014;3(June 2014):pp. 1-5. DOI: https://sites.google.com/site/asiapacificejournalofhss/journal-issues/june-2014.

7. Cho SC, Park MC, Keam B, et al. DDS, 4,4'-diaminodiphenylsulfone, extends organismic lifespan. Proc Natl Acad Sci U S A 2010;107(45):19326-19331. (In eng). DOI: $10.1073 /$ pnas.1005078107.

8. Cho SC, Rhim JH, Choi HR, et al. Protective effect of 4,4'-diaminodiphenylsulfone against paraquat-induced mouse lung injury. Exp Mol Med 2011;43(9):525-537. DOI: 10.3858/emm.2011.43.9.060.

9. Park SC. Serendipity in search for longevity from experiences of Hansen people. Transl Med Aging 2017;1:12-17. DOI: https://doi.org/10.1016/j.tma.2017.06.001.

10. Choi H, Cho SC, Ha YW, et al. DDS promotes longevity through a microbiome-mediated starvation signal. Transl Med Aging 2019;3:64-69. DOI: https://doi.org/10.1016/j.tma.2019.07.001.

11. Korea Legislation Research Institute. Dementia management act, act no. 15649, division of dementia policy of the ministry of health and welfare (MOHW): Korea Legislation Research Institute, 2018.

12. Hwang EJ, Park HA, Sohn SK, et al. Mapping Korean EDI medical procedure code to SNOMED CT. Stud Health Technol Inform 2019;264:178-182. DOI: 10.3233/SHTI190207.

13. Greenberg SM, Tennis MK, Brown LB, et al. Donepezil therapy in clinical practice: a randomized crossover study. Arch Neurol 2000;57(1):94-99. DOI: 10.1001/archneur.57.1.94.

14. Seltzer B, Zolnouni P, Nunez M, et al. Efficacy of donepezil in early-stage Alzheimer disease: a randomized placebo-controlled trial. Arch Neurol 2004;61(12):1852-1856. DOI: 10.1001/archneur.61.12.1852.

15. Tariot PN, Farlow MR, Grossberg GT, Graham SM, McDonald S, Gergel I. Memantine treatment in patients with moderate to severe Alzheimer disease already receiving donepezila randomized controlled trial. JAMA 2004;291(3):317-324. DOI: 10.1001/jama.291.3.317.

16. Farlow MR, Cummings JL. Effective pharmacologic management of Alzheimer's disease. Am J Med 2007;120(5):388-397. DOI: https://doi.org/10.1016/j.amjmed.2006.08.036.

17. Raina P, Santaguida P, Ismaila A, et al. Effectiveness of cholinesterase inhibitors and memantine for treating dementia: evidence review for a clinical practice guideline. Ann Intern Med 2008;148(5):379-397. DOI: 10.7326/0003-4819-148-5-200803040-00009\%m 18316756.

18. Lu PH, Edland SD, Teng E, Tingus K, Petersen RC, Cummings JL. Donepezil delays progression to AD in MCl subjects with depressive symptoms. Neurology 2009;72(24):2115-2121. DOI: 10.1212/WNL.0b013e3181aa52d3.

19. Lee JH, An HK, Sohn MG, Kivela P, Oh S. 4,4'-Diaminodiphenyl sulfone (DDS) as an inflammasome competitor. Int J Mol Sci 2020;21(17):5953. (https://www.mdpi.com/1422-0067/21/17/5953).

20. Courtney C, Farrell D, Gray R, et al. Long-term donepezil treatment in 565 patients with Alzheimer's disease (AD2000): randomised double-blind trial. Lancet 2004;363(9427):2105-2115. (In eng). DOI: 10.1016/s0140-6736(04)16499-4.

21. Petersen RC, Thomas RG, Grundman M, et al. Vitamin E and donepezil for the treatment of mild cognitive impairment. N Engl J Med 2005;352(23):23792388. DOI: $10.1056 /$ NEJMoa050151.

22. Feldman $\mathrm{HH}$, Ferris $\mathrm{S}$, Winblad B, et al. Effect of rivastigmine on delay to diagnosis of Alzheimer's disease from mild cognitive impairment: the InDDEx study. Lancet Neurol 2007;6(6):501-512. DOI: https://doi.org/10.1016/S1474-4422(07)70109-6.

23. Raschetti R, Albanese E, Vanacore N, Maggini M. Cholinesterase inhibitors in mild cognitive impairment: a systematic review of randomised trials. PLoS Med 2007;4(11):e338.

24. Dysken MW, Sano M, Asthana S, et al. Effect of Vitamin E and Memantine on Functional Decline in Alzheimer Disease: The TEAM-AD VA Cooperative Randomized Trial. JAMA 2014;311(1):33-44. DOI: 10.1001/jama.2013.282834.

25. Winblad B, Gauthier S, Scinto L, et al. Safety and efficacy of galantamine in subjects with mild cognitive impairment. Neurology 2008;70(22):2024-35. (In eng). DOI: 10.1212/01.wnl.0000303815.69777.26.

26. Schneider LS, Insel PS, Weiner MW, Alzheimer's Disease Neuroimaging Initiative. Treatment with cholinesterase inhibitors and memantine of patients in the Alzheimer's disease neuroimaging initiative. Arch Neurol 2011;68(1):58-66. DOI: 10.1001/archneurol.2010.343.

27. Hunderfund A, Roberts RO, Slusser T, et al. Mortality in amnestic mild cognitive impairment: a prospective community study. Neurology 2006;67(10):17641768.

28. Lee J. Living with/out dementia in contemporary South Korea. Med Anthropol Q 2019;33(4):501-516. (In eng). DOI: 10.1111/maq.12532.

29. Park YJ, Choe YJ, Park O, et al. Contact tracing during coronavirus disease outbreak, South Korea, 2020. Emerg Infect Dis 2020;26(10):2465-2468. (In eng). DOI: 10.3201/eid2610.201315.

30. Chon Y. The expansion of the Korean welfare state and its results@ focusing on lonł term care insurance for the elderly. Soc Policy Adm 2014;48:704720.

31. Lee SB. The community dementia reassurance center (chime ansim center) in South Korea. Ann Geriatr Med Res 2019;23(2):43-44. (In eng). DOI: 10.4235/agmr.19.0024.

32. Yonhap News. Gov't to take more responsibility for dementia patients. Yonhap News. Internet: Yonhap News Agency; 2017.

33. Nam HJ, Hwang SH, Kim YJ, Kim KW. Korean dementia observatory 2018. Seoul: Seoul Central Dementia Center, Ministry of Health and Welfare, 2018.

34. Youn H, Jeong HG. Pharmacotherapy for dementia. J Korean Med Assoc 2018;61(12):758-764. DOI: 10.5124/jkma.2018.61.12.758. 
35. Lee DW, Huh YS, Kim KW. Evidence-based treatment of Alzheimer's disease. J Korean Med Assoc 2009;52(4):417-425. DOI: https://doi.org/10.5124/jkma.2009.52.4.417.

36. Ahn SH, Choi NK, Kim YJ, et al. Drug persistency of cholinesterase inhibitors for patients with dementia of Alzheimer type in Korea. Arch Pharmacal Res 2015;38(6):1255-1262. DOI: 10.1007/s12272-014-0500-8.

37. Lee KU, Lee JH, Lee DY, et al. The effect of choline acetyltransferase genotype on donepezil treatment response in patients with Alzheimer's disease. Clin Psychopharmacol Neurosci 2015;13(2):168-173. (In eng). DOI: 10.9758/cpn.2015.13.2.168.

38. Hong YJ, Han HJ, Youn YC, et al. Safety and tolerability of donepezil $23 \mathrm{mg}$ with or without intermediate dose titration in patients with Alzheimer's disease taking donepezil $10 \mathrm{mg}$ : a multicenter, randomized, open-label, parallel-design, three-arm, prospective trial. Alzheimer's Res Ther 2019;11(1):37. DOI: 10.1186/s13195-019-0492-1.

39. Lee SJ, Seo HJ, Lee DY, Moon SH. Effects of a dementia screening program on healthcare utilization in South Korea: a difference-in-difference analysis. Int J Environ Res Public Health 2019;16(20):3837. (https://www.mdpi.com/1660-4601/16/20/3837).

40. Kang HS, Yun J-H, Mooon Y-J, et al. Comparative assessment of clinical efficacy between the naive and the switching group to donepezil: 12 months prospective study. J Korean Geriatr Psychiatry 2010;14(2):111-117. (https://kmbase.medric.or.kr/Main.aspx? $\mathrm{d}=$ KMBASE\& $\mathrm{i}=0869220100140020111 \& \mathrm{~m}=\mathrm{VIEW})$.

41. Kang HS, Yun JH, Ahn IS, et al. Effects of galantamine treatment on attention, activities of daily living, and neuropsychiatric symptoms between the patients with pure Alzheimer's disease and mixed dementia. J Korean Geriatr Psychiatry 2012;16(1):24-30.

42. Yu KH. Taking the fight to Alzheimer's disease: Korea JoongAng Daily in association with the New York Times, 2011.

43. Lee DY. [Editor Kim Nam-Jung goes] Patients who haven't used dementia medicine, $90 \%$ of them are severe after 8 years... What if? In: Nam-Jung K, ed. Seoul National University Hospital: JoongAng Ilbo; 2018.

44. Möllers T, Perna L, Stocker H, et al. New use of psychotropic medication after hospitalization among people with dementia. Int J Geriatr Psychiatry 2020;35(6):640-649.

45. Stingl J, Just K, Schurig M, et al. Prevalence of Psychotropic Drugs in Cases of Severe Adverse Drug Reactions Leading to Unplanned Emergency Visits in General Hospitals. Pharmacopsychiatry 2020;53(3):133.

46. Jordan S, Banner T, Gabe-Walters M, et al. Nurse-led medicines' monitoring in care homes, implementing the Adverse Drug Reaction (ADRe) Profile improvement initiative for mental health medicines: An observational and interview study. PLoS One 2019;14(9):e0220885.

47. Stone M. Mortality and antipsychotic drug use in dementia-related behavioral disorders. US Department of Health and Human Services: Food and Drug Administration, Center for Drug Evaluation and Research, 2005.

48. Du Y, Wolf IK, Busch MA, Knopf H. Associations between the use of specific psychotropic drugs and all-cause mortality among older adults in Germany: Results of the mortality follow-up of the German National Health Interview and Examination Survey 1998. PLoS One 2019;14(1):e0210695.

49. Ralph SJ, Espinet AJ. Increased All-Cause Mortality by Antipsychotic Drugs: Updated Review and Meta-Analysis in Dementia and General Mental Health Care. J Alzheimers Dis Rep 2018;2(1):1-26. DOI: 10.3233/ADR-170042.

50. Dharmarajan TS, Choi H, Hossain N, et al. Deprescribing as a clinical improvement focus. J Am Med Dir Assoc 2020;21(3):355-360.

51. Campbell NL, Perkins AJ, Gao S, et al. Adherence and tolerability of Alzheimer's disease medications: a pragmatic randomized trial. J Am Geriatr Soc 2017;65(7):1497-1504. DOI: https://doi.org/10.1111/jgs.14827.

52. Mendez MF, Shapira JS, McMurtray A, Licht E. Preliminary findings: behavioral worsening on donepezil in patients with frontotemporal dementia. Am J Geriatr Psychiatry 2007;15(1):84-87. DOI: https://doi.org/10.1097/01.JGP.0000231744.69631.33.

53. Lee JH, Choi SH, Lee CJ, Oh SS. Recovery of dementia syndrome following treatment of brain inflammation. Dement Geriatr Cogn Disord Extra 2020;10(1):1-12. DOI: 10.1159/000504880.

54. Lee JH, Lee CJ, Park J, Lee SJ. The neuro-inflammasome in Alzheimer's disease and cerebral stroke. (https://osf.io/y2ugc/).

55. Lee JH, Lee CJ, Park J, Lee SJ, Choi SH, Oh SS. The preventive and treatment of the neuro-inflammasome in Sorokdo national hospital. Sci Rep. (https://doi.org/10.21203/rs.3.rs-243831/v1).

56. Birks JS. Cholinesterase inhibitors for Alzheimer's disease. Cochrane Database Syst Rev.

57. Howe EG. Ethical issues in diagnosing and treating Alzheimer disease. Psychiatry (Edgmont (Pa : Township)) 2006;3(5):43-53. (In eng) (https://pubmed.ncbi.nlm.nih.gov/21103177, https://www.ncbi.nlm.nih.gov/pmc/articles/PMC2990623/).

58. Canevelli M, Vanacore N, Blasimme A, Bruno G, Cesari M. Overtreating Alzheimer's disease. J Prev Alzheimer's Dis 2021;8(2):234-236. DOI: 10.14283/jpad.2020.74.

59. Kho J, loannou A, Mandal AKJ, et al. Long term use of donepezil and QTc prolongation. Clin Toxicol (Phila) 2021;59(3):208-214. DOI: 10.1080/15563650.2020.1788054.

60. Xu H, Garcia-Ptacek S, Jönsson L, Anders W, Nordström P, Eriksdotter M. Long term effects of cholinesterase inhibitors on cognitive decline and mortality. Neurology. (https://n.neurology.org/content/neurology/early/2021/03/19/WNL.0000000000011832.full.pdf).

61. Bhattacharjee S, Patanwala AE, Lo-Ciganic WH, et al. Alzheimer's disease medication and risk of all-cause mortality and all-cause hospitalization: A retrospective cohort study. Alzheimers Dement Transl Res Clin Interv 2019;5(1):294-302. DOI: https://doi.org/10.1016/j.trci.2019.05.005.

62. Lee J-H, An HK, Sohn M-G, Kivela P, Oh S. 4,4'-Diaminodiphenyl Sulfone (DDS) as an Inflammasome Competitor. International Journal of Molecular Sciences 2020;21(17):5953. DOI: 10.3390/ijms21175953. 
63. Lee J-h, Lee CJ, Park J, Lee SJ, Su-Hee C. The neuro-inflammasome in Alzheimer's disease and cerebral stroke. Dementia and Geriatric Cognitive Disorders EXTRA 2021;Accepted. 2020.3.13 (research article). DOI: 10.31219/osf.io/ed9mb.

64. Jong-hoon L, Chul Joong L, Jungwuk P, So Jeong L, Su-Hee C, Sang-Suk O. The Preventive and Treatment of the Neuro-Inflammasome in Sorokdo National Hospital. Scientific Reports 2021;under review. DOI: 10.21203/rs.3.rs-243831/v1.

65. Huang W, Foster JA, Rogachefsky AS. Pharmacology of botulinum toxin. J Am Acad Dermatol 2000;43(2, Part 1):249-259. DOI: https://doi.org/10.1067/mjd.2000.105567.

66. Tzeng MC, Cohen RS, Siekevitz P. Release of neurotransmitters and depletion of synaptic vesicles in cerebral cortex slices by alpha-latrotoxin from black widow spider venom. Proc Natl Acad Sci U S A 1978;75(8):4016-4020. DOI: 10.1073/pnas.75.8.4016.

67. Yan S, Wang X. Recent Advances in Research on Widow Spider Venoms and Toxins. Toxins 2015;7(12):5055-5067. (https://www.mdpi.com/2072$6651 / 7 / 12 / 4862)$.

68. Birdsall NJ, Curtis CA, Eveleigh P, et al. Muscarinic receptor subtypes and the selectivity of agonists and antagonists. Pharmacology 1988;37 Suppl 1:2231. (In eng). DOI: 10.1159/000138503.

69. Lebois EP, Thorn C, Edgerton JR, Popiolek M, Xi S. Muscarinic receptor subtype distribution in the central nervous system and relevance to aging and Alzheimer's disease. Neuropharmacology 2018;136(Pt C):362-373. (In eng). DOI: 10.1016/j.neuropharm.2017.11.018.

70. Wessler I, Kirkpatrick CJ. Acetylcholine beyond neurons: the non-neuronal cholinergic system in humans. Br J Pharmacol 2008;154(8):1558-1571. DOI: https://doi.org/10.1038/bjp.2008.185.

71. Saternos HC, Almarghalani DA, Gibson HM, et al. Distribution and function of the muscarinic receptor subtypes in the cardiovascular system. Physiol Genom 2018;50(1):1-9. DOI: 10.1152/physiolgenomics.00062.2017.

72. Lee JH, Kanwar B, Balentine J, Lee CJ, Khattak A, Sergi C. The method and results of a treatment targeting SARS-CoV-2-activated inflammasomes. Nat Commun. (Review) (https://doi.org/10.31219/osf.io/jq5tc).

73. Lee JH. Commentary for the elderly in the pandemic era: Karger, 2021.

\section{Declarations}

\section{Acknowledgements}

Sister Marianne Stoeger and Sister Margaritha Pissarek are two Austrian nurses. They attended members of the Catholic Church of Christ Kingdom Ladies' Association did not hesitate to pack their luggage at the local Catholic bishop's words, "We need a nurse to take care of the Hansen people in Sorok Island, Korea." They volunteered to care for patients as part of a 5-year project at a Korean 'leper colony'. After graduating from her nursing school at the University of Innsbruck Nursing School in Tyrol, Western Austria, Marianne, who worked at a hospital in Innsbruck, joined Sorok Island in February 1962 . She was 28 years old at the time. Sister Margaritha, her nursing school roommate, entered Sorok Island in October 1967. This study was conducted from 2005 to 2020 based on the medical records of Sorokdo National Hospital. However, the patient research in the report was initiated by Sister Marianne Stoeger and Sister Margaritha Pissarek. Sister Marianne and Sister Margaritha left Sorok island on November 21, 2005, returned to their homeland. They stayed for 40 years and spent their wages on supplies and their work effectively unpaid. When HD patients were treated with fear, suspicion and cruelty, these two nurses showed exceptional compassion for their patients. So we decided to call this study 'Marianne and Margaritha's deprescribing treatment for human survival'.

This study deals with society's pathology, which we learned about during a long journey to treat a person with Alzheimer's disease, who went to heaven on January 3 this year. This study is published through a major journal, replacing the person's obituary.

\section{Funding}

No funding

\section{Author Contributions}

$J L$ designed the study, developed the hidden equation, analyzed the data, and wrote the paper.

\section{Additional Information}

\section{Competing Interests}

The author(s) declare no competing interests.

\section{Tables}

Table 1. NHIS dementia medicines: users and deaths toll 


\begin{tabular}{|c|c|c|c|c|c|c|c|c|c|c|c|c|c|c|c|c|c|c|c|c|}
\hline \multirow{2}{*}{ Year } & \multicolumn{2}{|c|}{ AAD } & \multicolumn{2}{|c|}{ Donepezil } & \multicolumn{2}{|c|}{ Rivastigmine } & \multicolumn{2}{|c|}{ Memantine } & \multicolumn{2}{|c|}{ Risperidone } & \multicolumn{2}{|c|}{ Fluoxetine } & \multicolumn{2}{|c|}{ Olanzapine } & \multicolumn{2}{|c|}{ Sertraline } & \multicolumn{2}{|c|}{ Quetiapine } & \multicolumn{2}{|c|}{$\overline{\text { Aripiprazol } \epsilon}$} \\
\hline & User & Death & User & Death & User & Death & user & death & user & death & user & death & user & death & user & death & user & death & user & $\overline{\mathrm{de} e \bar{c}}$ \\
\hline 2010 & $1,496,235$ & 78,528 & 96,820 & 12,575 & 8,070 & 780 & 31,965 & 5,559 & 181728 & 8945 & 156,899 & 1,802 & 37,810 & 1,654 & 71,494 & 1,341 & 140,218 & 10,654 & 25,155 & $\overline{3}$ \\
\hline 2011 & $1,624,963$ & 87,053 & 123,101 & 15,79 & 9,788 & 850 & 35,315 & 5,945 & 186077 & 976 & 151,252 & 1,580 & 45,177 & 2,001 & 76,809 & 1,319 & 172,218 & 13,466 & 28,561 & $\overline{3}$ \\
\hline 2012 & $1,793,974$ & 100,711 & 150,128 & 19,604 & 11,218 & 1,103 & 37,138 & 6,419 & 191121 & 9519 & 150,654 & 1,582 & 54,344 & 2,681 & 85,193 & 1,377 & 202,486 & 17,654 & 37,290 & $\overline{4}$ \\
\hline 2013 & $1,879,280$ & 109,772 & 176,440 & 22,941 & 11,935 & 1,170 & 38,391 & 6,403 & 189702 & 9354 & 140,194 & 1,439 & 59,184 & 3,112 & 86,931 & 1,427 & 228,140 & 21,117 & 45,297 & $\overline{5}$ \\
\hline 2014 & $2,028,410$ & 119,542 & 204,724 & 26,636 & 13,705 & 1,291 & 43,165 & 6,568 & 190178 & 9271 & 134,013 & 1,395 & 63,444 & 3,276 & 89,114 & 1,565 & 259,635 & 24,520 & 67,152 & 7 \\
\hline 2016 & $2,373,538$ & 148,351 & 267,241 & 36,375 & 15,103 & 1,682 & 58,626 & 9,080 & 199776 & 10396 & 137,846 & 1,329 & 66,902 & 3,368 & 103,099 & 1,684 & 331,811 & 32,972 & 102,241 & $\overline{1,1}$ \\
\hline 2017 & $2,598,416$ & 167,853 & 294,203 & 42,187 & 14,443 & 1,716 & 65,605 & 10,718 & 203635 & 10822 & 144,496 & 1,268 & 75,153 & 3,700 & 115,370 & 1,853 & 384,209 & 39,984 & 133,075 & $\overline{1,4}$ \\
\hline 2018 & $2,880,654$ & 185,099 & 319,751 & 47,487 & 14,777 & 1,839 & 70,873 & 11,597 & 208994 & 11179 & 157,170 & 1,369 & 81,868 & 4,042 & 129,710 & 1,982 & 439,704 & 46,257 & 174,861 & $\overline{1,8}$ \\
\hline 2019 & $3,234,536$ & 197,232 & 336,683 & 48,830 & 14,964 & 1,840 & 79,770 & 12,714 & 228123 & 12044 & 173,284 & 1,405 & 87,565 & 4,359 & 142,660 & 2,005 & 540,397 & 51,767 & 214,761 & $\overline{2,2}$ \\
\hline
\end{tabular}

Table 2. Lee's hidden data and results of calculation

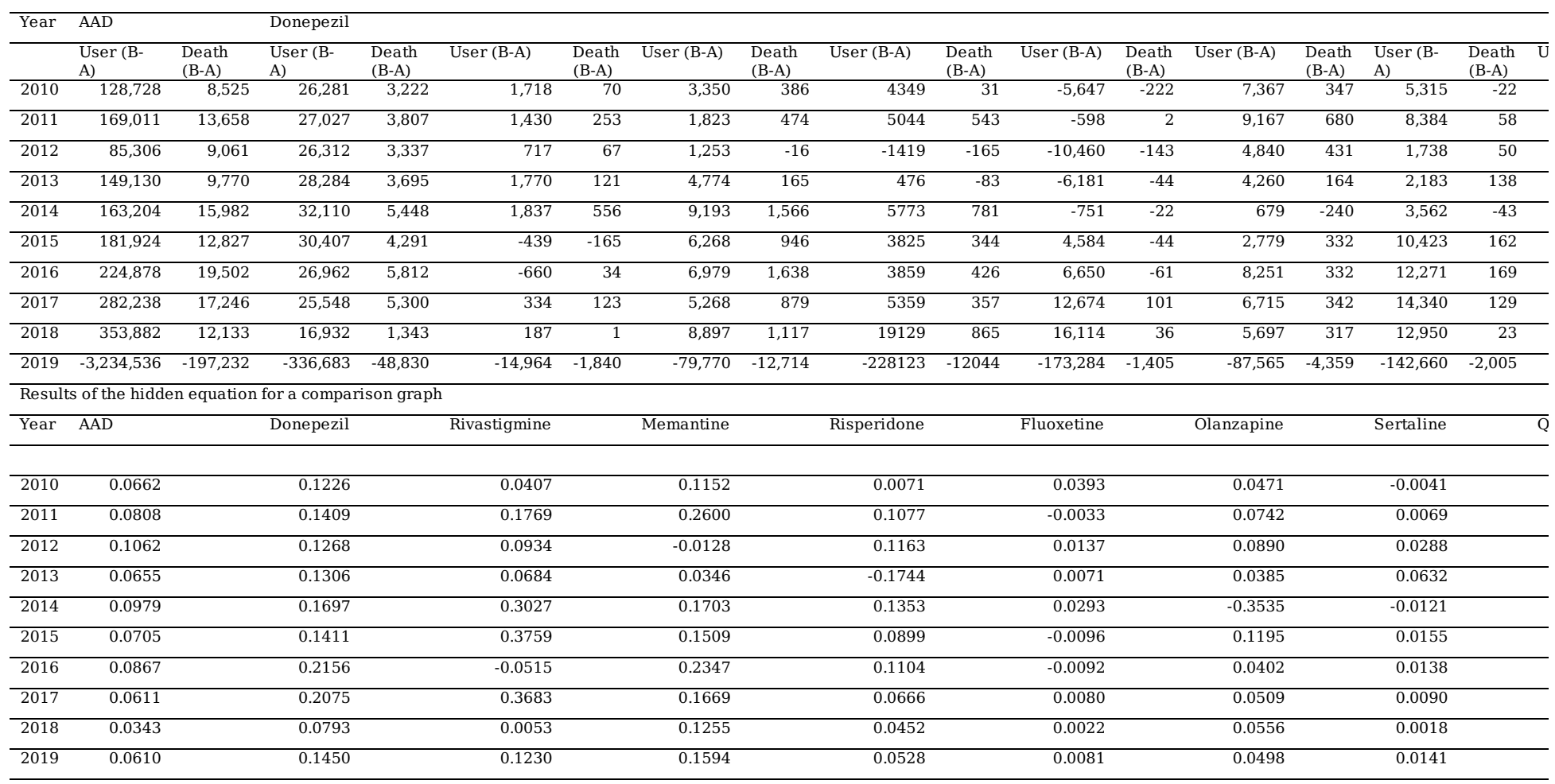

\section{Figures}




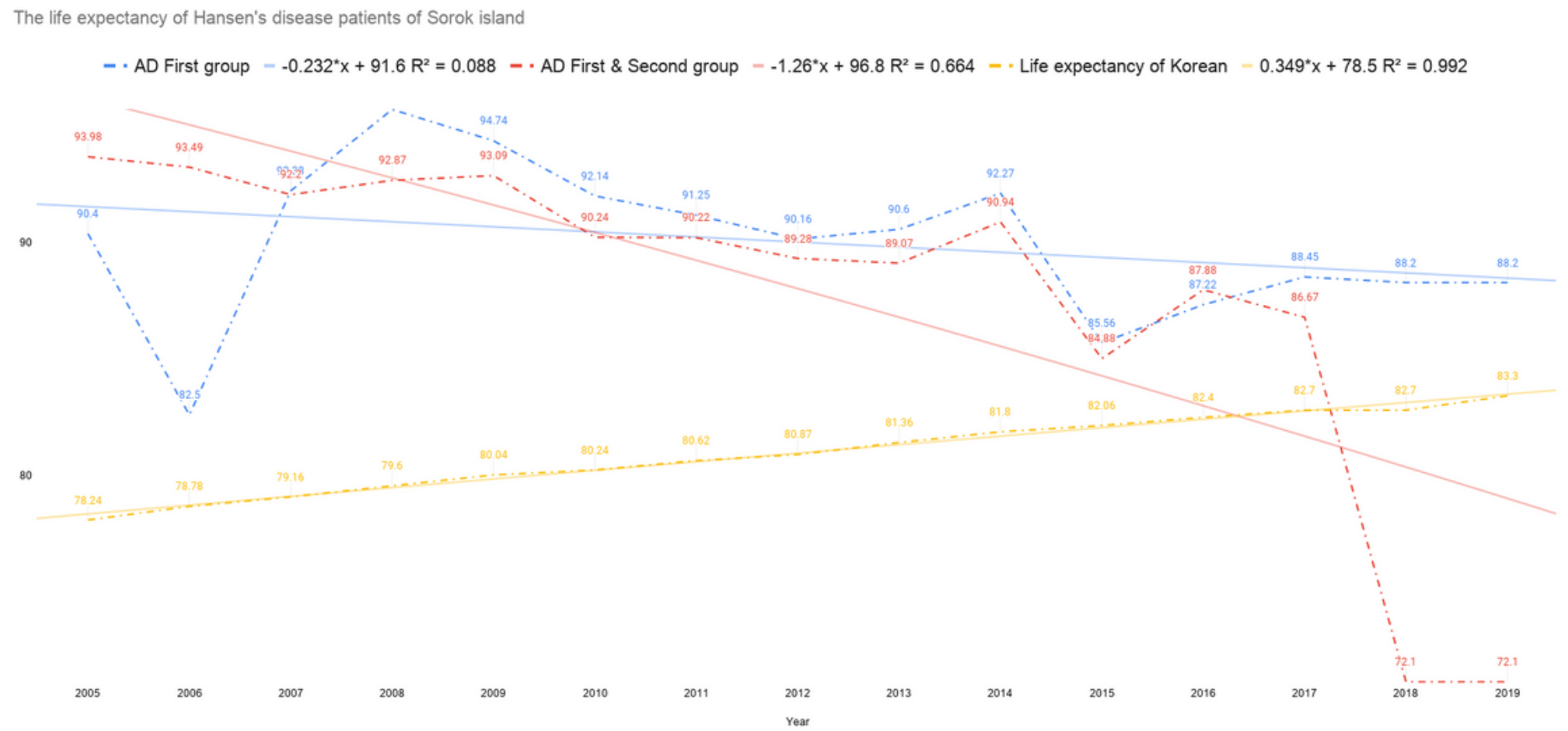

\section{Figure 1}

The life expectancy of Hansen's disease patients with Alzheimer's disease at Sorokdo National Hospital. In the group of patients diagnosed with Alzheimer's disease, the mean age of deaths while taking only dementia symptom treatment was blue. The mean age of deaths with taking additional psychiatric drugs is red. In 2018-2019, the life expectancies of HD patients taking additional psychotropic medications were suddenly decreased in the Sorokdo National Hospital. On the other hand, Korean's life expectancy is on the rise (see yellow). The life expectancies of HD patients taking the AAD first group (blue) were decreased in the Sorokdo National Hospital. 


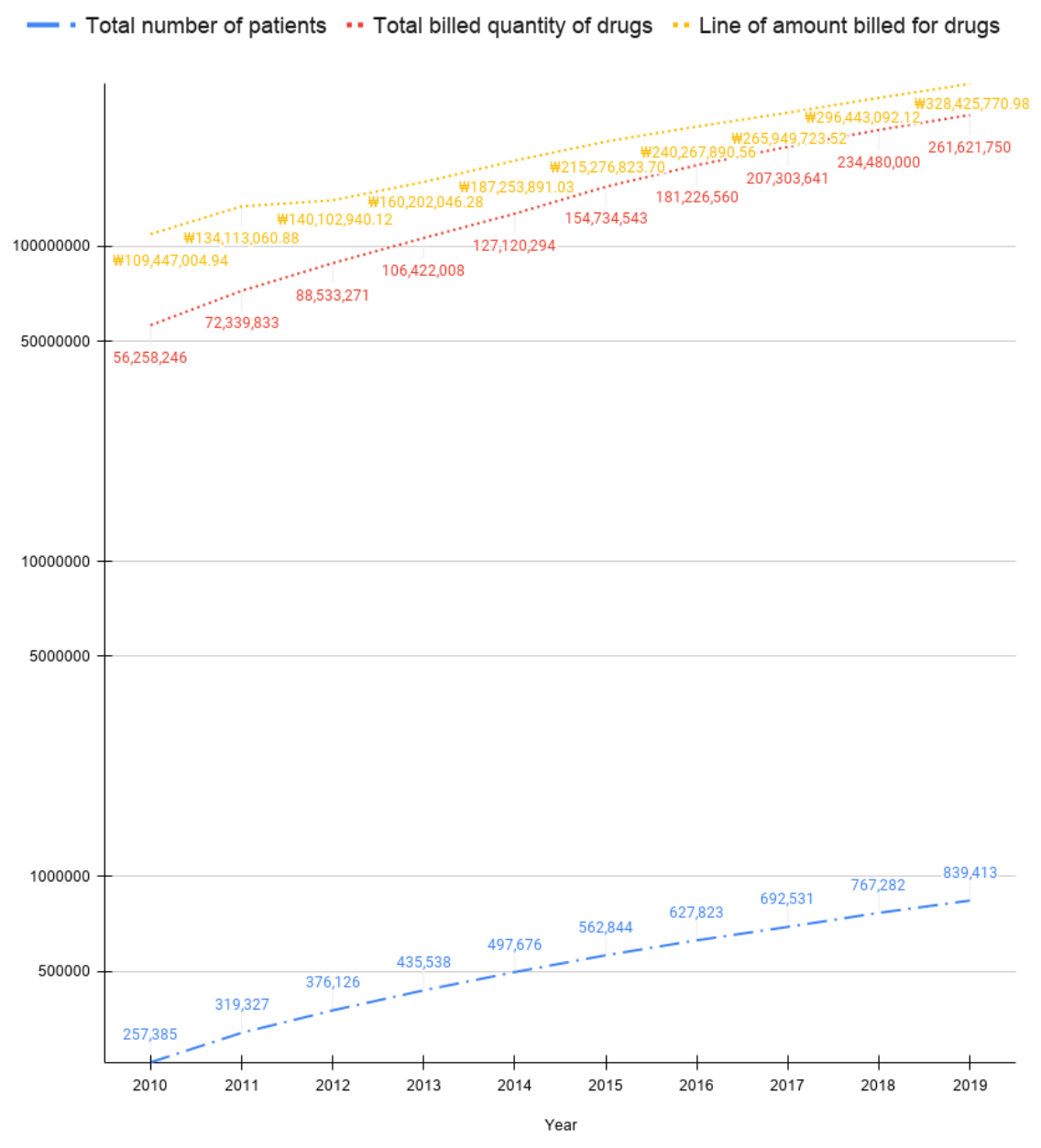

\section{Figure 2}

Numbers of drug prescriptions for dementia patients in Korea from 2010 to 2019 . The state or local government subsidises dementia patients for expenses incurred in the treatment and diagnosis of dementia from its budget, considering each dementia patient's capability to bear such costs. The $A D$ and $A A D$ data were reported from the Health Insurance Review \& Assessment system. From 2010 to June 2020, the diagnosis and prescription of patients with MCI and AD in Korea increased 3.26 times and 4.65 times, respectively. 


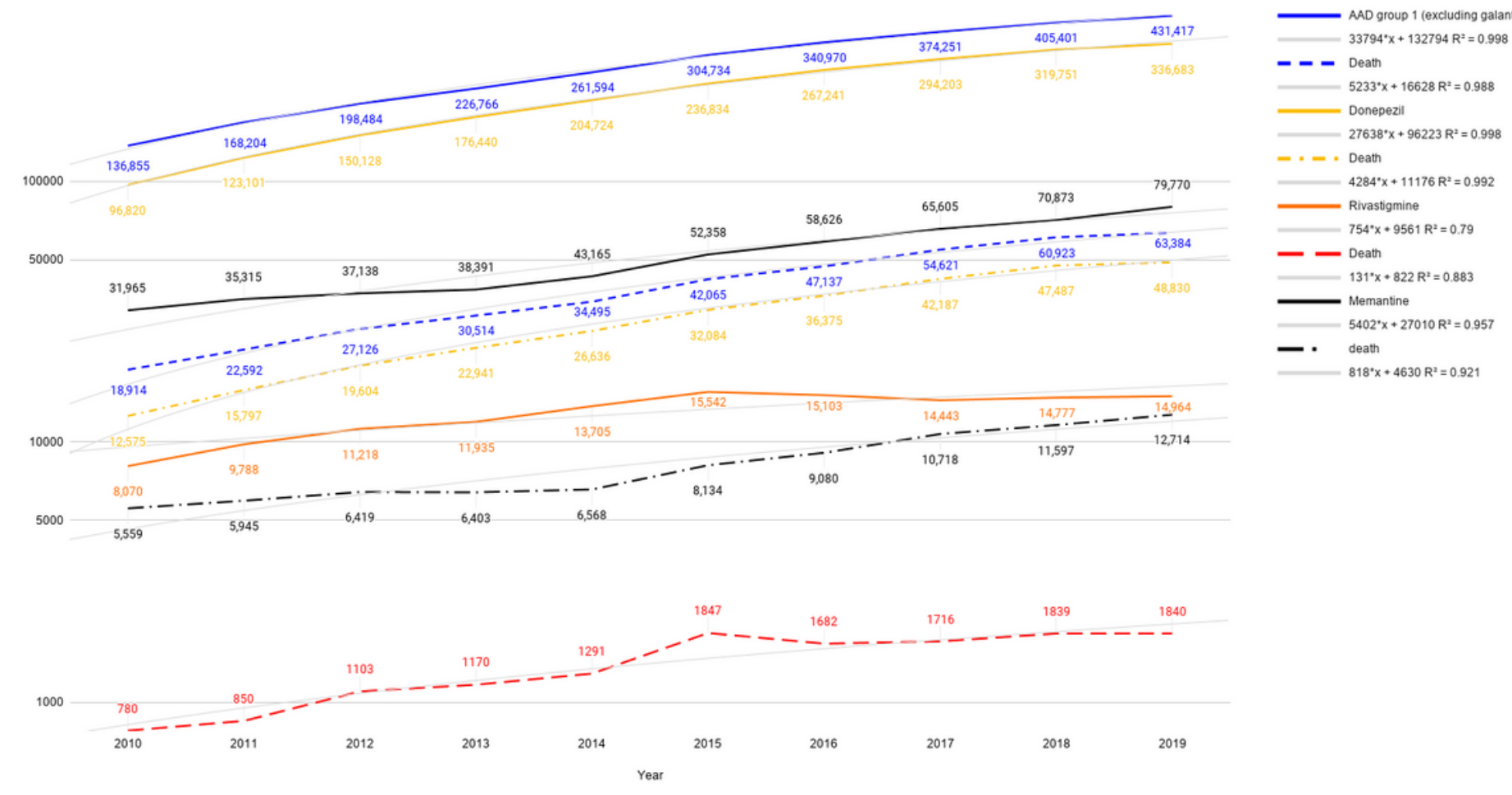

Figure 3

Graph with AAD users and deaths in Korea from 2010 to 2019. The number of users who took AAD in Korea increased 2.16 times, and the number of deaths increased by 2.51 times from 2010 to June 2019. The life expectancy between AD and AAD was significantly observed between 2017 and 2019 . It is because the DMA was strengthened on June 12, 2018. Doctors do not prescribe donepezil, rivastigmine, galantamine, or memantine in duplicate to patients. However, since psychotropic medication can be added to four drugs, we exclude psychotropic medication in AAD. This study also excluded galantamine, which was among the others group with psychotropic medication. The DMA was strengthened on June 12, 2018. The number of users who took donepezil in Korea increased 3.48 times, and the number of deaths increased 3.88 times from 2010 to June 2019. The number of users who took rivastigmine in Korea increased 1.85 times, and the number of deaths increased 2.36 times from 2010 to June 2019 . The number of users who took memantine in Korea increased 2.50 times, and the number of deaths increased by 2.29 times from 2010 to June 2019. 


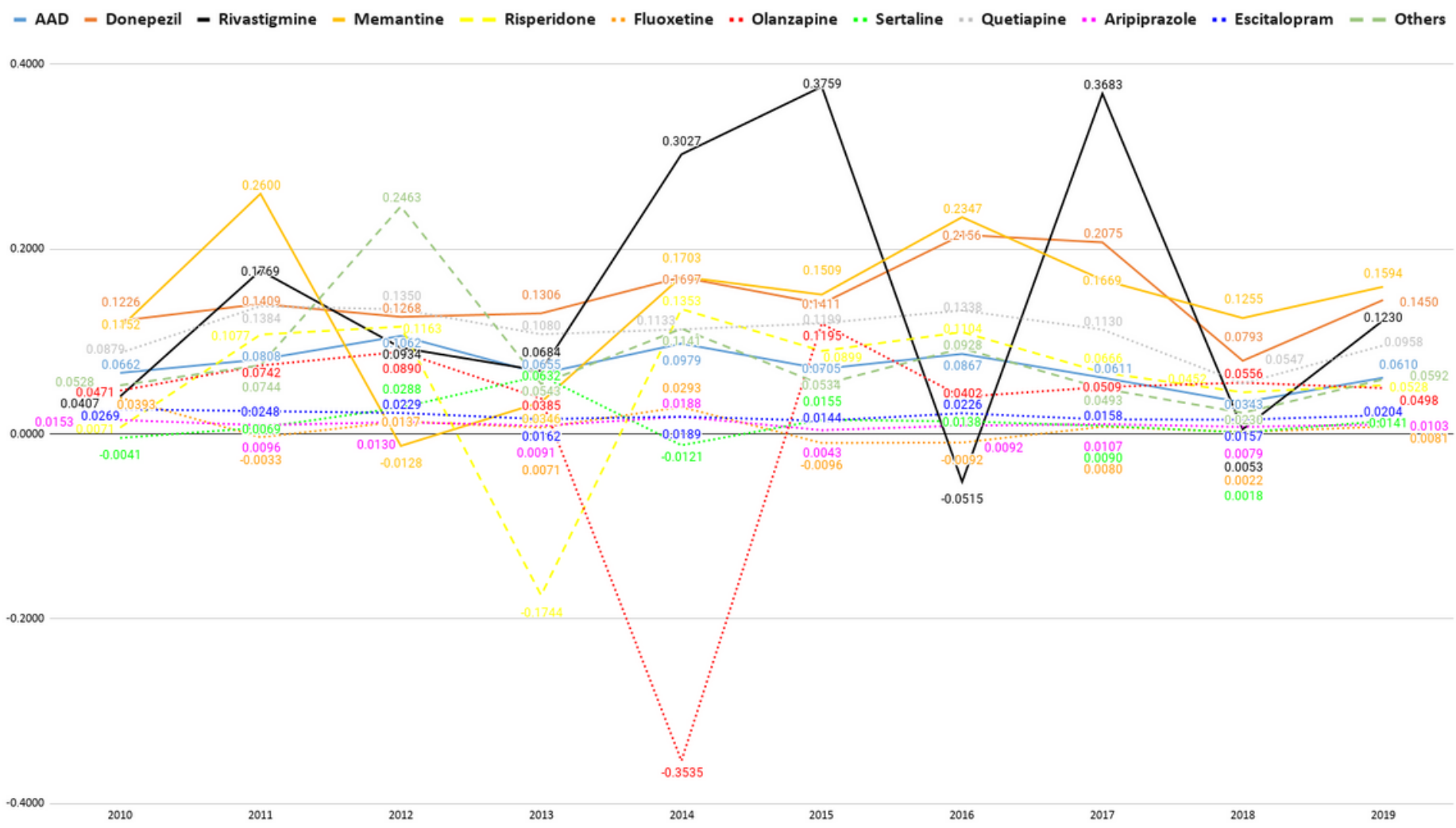

\section{Figure 4}

Lee's hidden equation graph with AAD users and deaths in Korea from 2010 to 2019. The number of deaths is the independent variable. Lee's hidden equation follows. $X$ is the year, $Y$ is (death $B$ - death $A$ )/(user B - user A). By comparing the rate at which the number of deaths increases when the number of users increases, we can compare deaths caused by dementia medicines. The population is all Koreans. If the independent variables are AAD, donepezil, rivastigmine, memantine, risperidone, fluoxetine, olanzapine, sertraline, quetiapine, aripiprazole, escitalopram, and others, the dependent variable is Lee's hidden data. It allows us to calculate the F-ratio value and the p-value by the one-way repeated measures ANOVA calculator. 

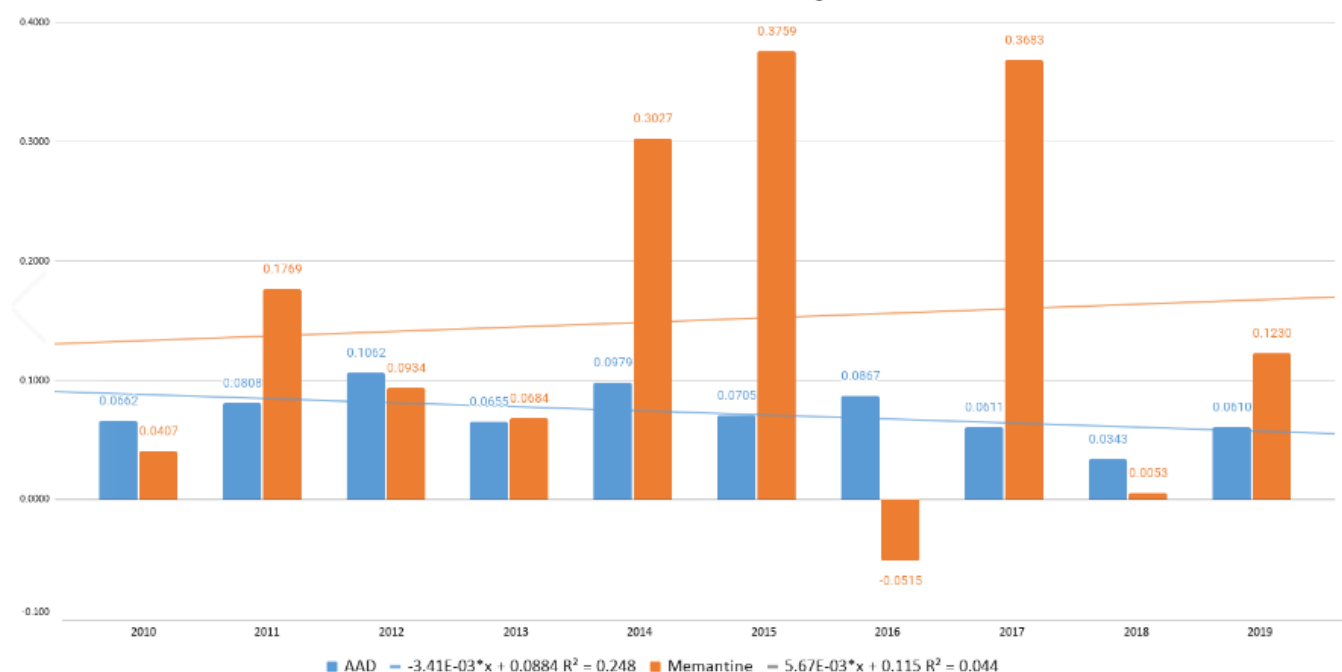

0.3

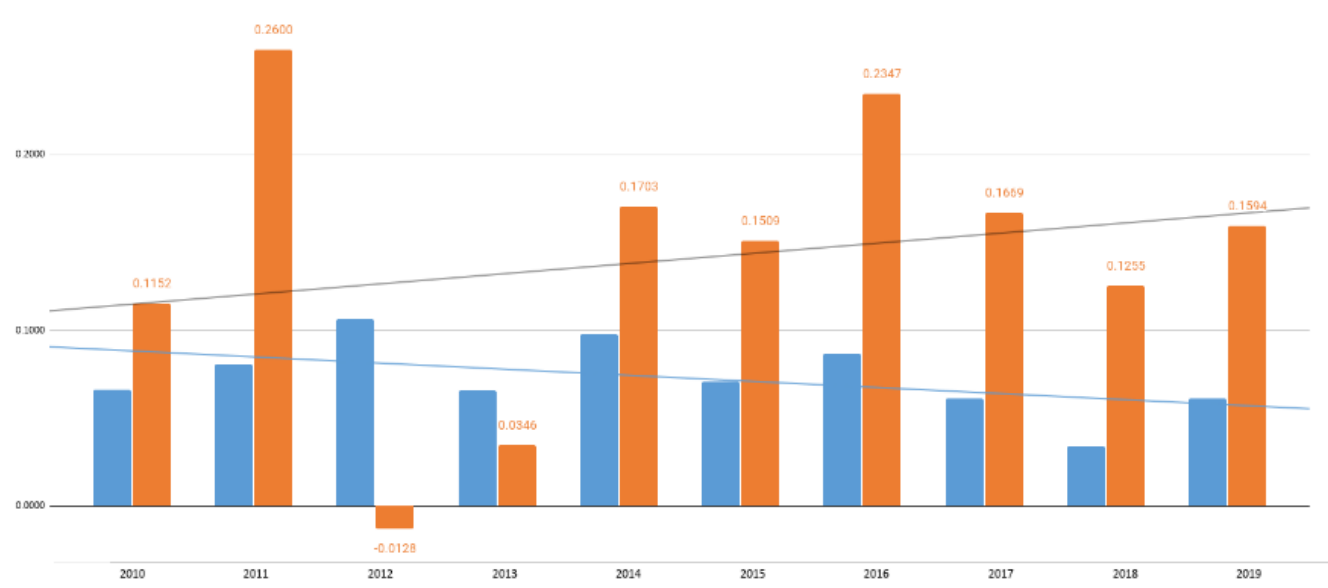

Figure 5

Lee's hidden equation graph with users and deaths in Korea from 2010 to 2019 . The number of users who took rivastigmine in Korea increased 1.84 times, and the number of deaths increased by 2.36 times from 2010 to June 2019. The number of users who took AAD in Korea increased 2.16 times, and the number of deaths increased by 2.51 times from 2010 to June 2019. The rivastigmine trend line is black. The trend line of AAD, the reference line, is blue. The pattern of change for rivastigmine is jagged in the hidden equation graph, but the death toll keeps increasing. The number of users who took memantine in Korea increased 2.50 times, and the number of deaths increased by 2.29 times from 2010 to June 2019. Memantine is an uncompetitive NMDA receptor modulator. It is prescribed to treat moderate-to-severe AD. The number of users who took AAD in Korea increased 2.16 times, and the number of deaths increased by 2.51 times from 2010 to June 2019. The memantine trend line is black. The trend line of AAD, the reference line, is blue. Memantine did not significantly increase the number of deaths compared to the increase in users, but the death toll increases in the hidden equation graph. 

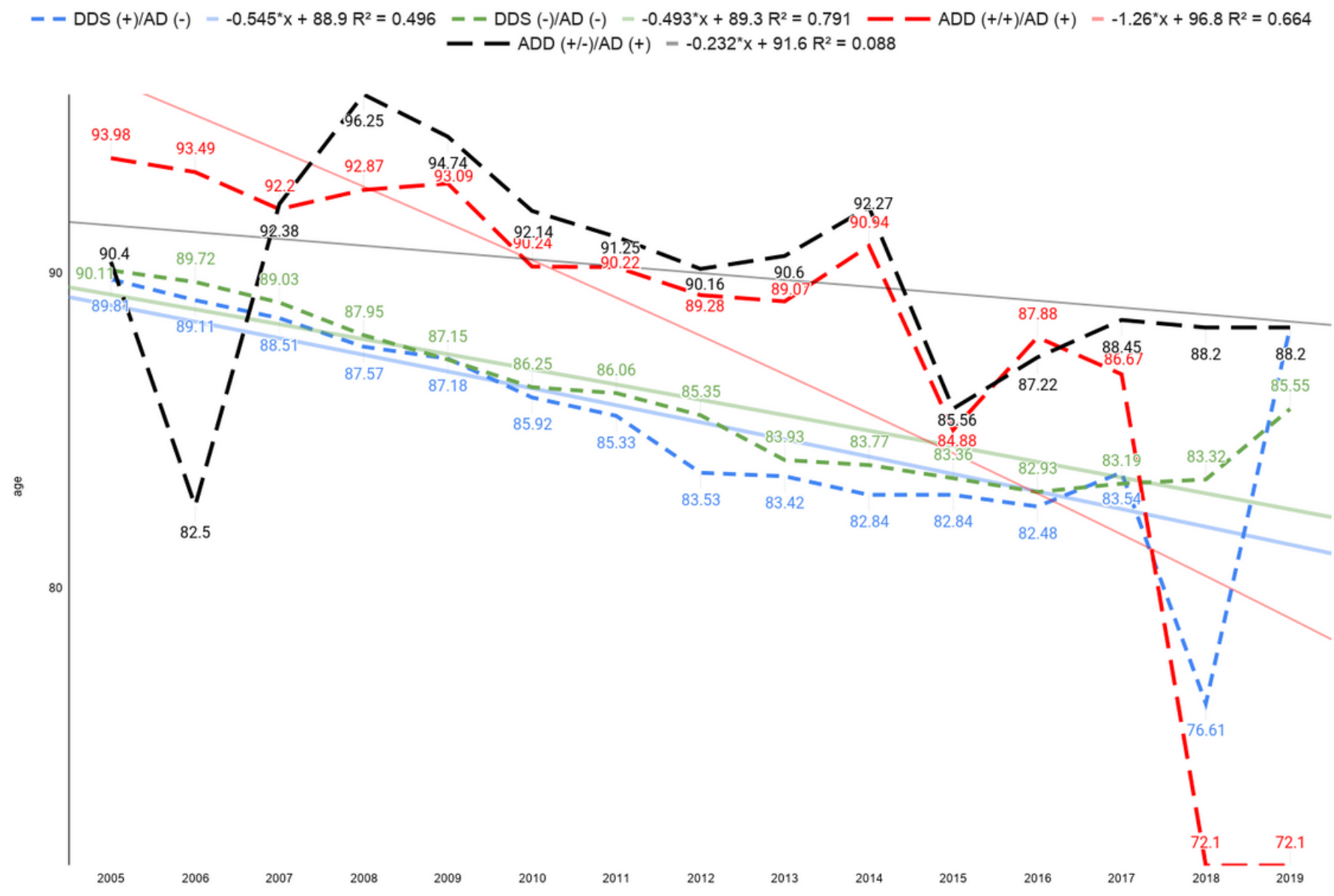

\section{Figure 6}

The life expectancy of the four groups of Hansen's disease patients at Sorokdo National Hospital We searched all medical records of the Sorokdo National Hospital when the International Classification of Diseases (ICD)-9 code and Electronic Data Interchange (EDI) were computerised by medical staff. We analysed medical data on the correlation between AAD 1, 2 groups and AD with the ICD-9 and -10 codes. 1.AD group with AAD 1 (+) and AAD 2 (-): In the group of patients diagnosed with Alzheimer's disease, the mean age of deaths while taking only dementia symptom treatment was red. 2.AD group with AAD 1 ( + ) and AAD $2(+)$ : In the group of patients diagnosed with Alzheimer's disease, the mean age of deaths while taking dementia symptom treatment and psychotropic medications was black. 3.AD free group with DDS (+): In patients free of Alzheimer's disease, the mean age of deaths while taking dapsone was blue. 4.AD free group with DDS (-): In patients free of Alzheimer's disease, the mean age of deaths while not taking dapsone was green. 


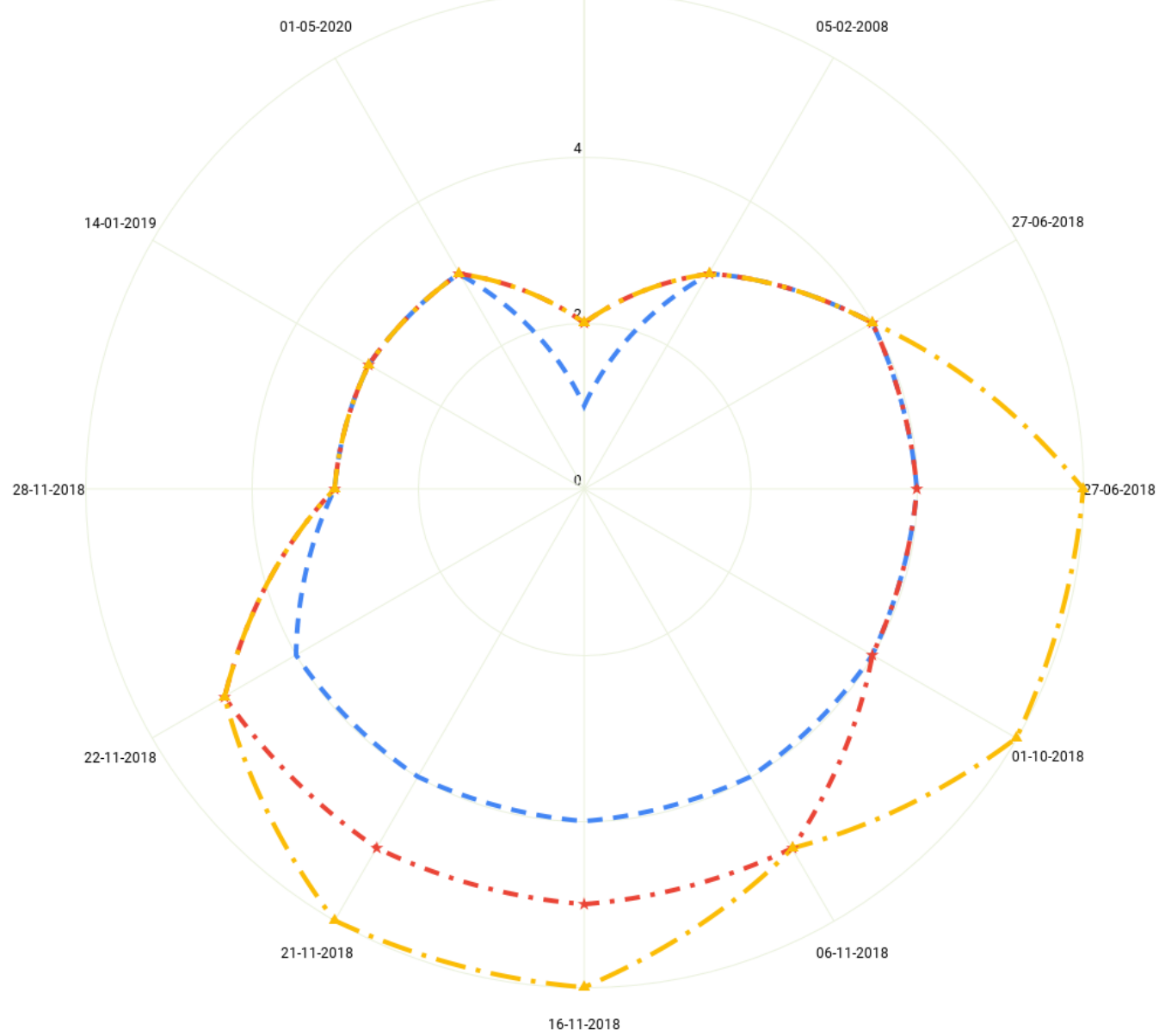

\section{Figure 7}

The ranges of syndromal staging of the cognitive continuum, numeric clinical staging, and numeric clinical staging + biomarker (D) were indicated using a radial chart. The range of the syndromal staging of the cognitive continuum, the numeric clinical staging standard, and numeric clinical staging + biomarker (D) was expressed when patients were deteriorated due to AAD. While monitoring the AD patient's condition, acetylcholine precursor was prescribed in the hospital's intensive care unit to the patient who had a stroke but medical staffs were not aware of the neurological symptoms caused by the acetylcholine precursor' side effects54. If AAD itself was not staged as a biomarker (D), the patient should be restrained to a bed, and it made the patient's condition worse. The numeric clinical staging + biomarker (D) of the patient (yellow) was 2007 stage $2 \rightarrow$ 05-02-2008 Stage 3 $\rightarrow$ 27-06-2018 Stage 4 $\rightarrow$ 27-06-2018 01-10-2018 Stage $6 \rightarrow$ 06-11-2018 Stage $5 \rightarrow$ 16-11-2018 Stage $6 \rightarrow$ 21-11-2018 Stage $6 \rightarrow$ 22-11-2018 Stage 5 $\rightarrow$ 28-11-2018 01-05-2019 Stage 3, but the numeric clinical

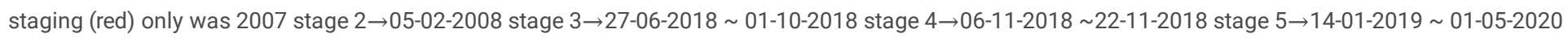
stage 371. The management standard for $A D$ will be further expanded if the numeric clinical staging includes side effects of donepezil (AAD) as a biomarker (D).

\section{Supplementary Files}

This is a list of supplementary files associated with this preprint. Click to download.

- SupplementaryMaterials.docx

- supplfigureDementiaManagementActandDeathToll.zip

- STROBEchecklist.docx 